\title{
Relationship between Physical Activity and Fatigue in Adults with Cystic Fibrosis
}

\author{
Carly Orava, BScKin, MScPT; Jennifer Fitzgerald, BScKin, MScPT; \\ Stephen Figliomeni, HBK, MScPT; Danette Lam, BScKin, MScPT; \\ Anthony Naccarato, BScKin, MScPT; Erika Szego, BEd, MScPT; ${ }^{*}$ \\ Karen Yoshida, BPHE, BScPT, MSc, PhD; ${ }^{*}$ Pat Fox, BScPT, MSc; ${ }^{*}$ \\ Jenna Sykes, BMath, MMath ${ }^{\dagger}$ Kenneth Wu, MA(SocSci), BScPT, MBA ${ }^{* \dagger}$
}

\begin{abstract}
Purpose: We examined the relationship between the amount of physical activity and level of fatigue in adults with cystic fibrosis (CF). Method: Participants were recruited from the Toronto Adult Cystic Fibrosis Centre at St. Michael's Hospital. Participants completed the Habitual Activity Estimation Scale, the Multidimensional Fatigue Inventory, and the Depression subscale of the Hospital Anxiety and Depression Scale, in that order. Descriptive statistics and linear and multiple regressions were computed. Results: Over a 6-month period, 51 individuals were approached, and 22 (10 men, 12 women) participated in this study. The participants' median age was 33 , and forced expiratory volume in 1 second $\left(\mathrm{FEV}_{1}\right)$ was $64 \%$ predicted. When holding both FEV and $_{1}$ depression constant, a significant negative correlation was found between total active hours per weekday and general fatigue $(\beta=-0.735, p=0.03)$; there was a negative trend between total active hours per weekday and physical fatigue ( $\beta=-0.579, p=0.09)$. Conclusions: This study is the first to demonstrate that among adults with $\mathrm{CF}$, a higher level of physical activity is associated with a lower level of general and physical fatigue when controlling for lung function and level of depression. Physical activity may be used as a means of mitigating the levels of general and physical fatigue in people with CF.
\end{abstract}

Key Words: adult; cystic fibrosis; exercise; fatigue.

\section{RÉSUMÉ}

Objectif: des chercheurs ont examiné la relation entre la quantité d'activité physique et le taux de fatigue chez des adultes atteints de fibrose kystique (FK). Méthodologie : les chercheurs ont recruté les sujets au sein du centre de FK pour adultes du St. Michael's Hôpital de Toronto. Ils leur ont fait remplir, dans l'ordre, l'échelle d'évaluation de l'activité habituelle, l'inventaire de fatigue multidimensionnelle et la sous-échelle de dépression de l'échelle d'anxiété et de dépression en milieu hospitalier. Ils ont calculé les statistiques descriptives et les régressions linéaires et multiples. Résultats: Sur une période de six mois, les chercheurs ont sollicité 51 personnes, dont 22 (10 hommes) ont participé à l'étude. Ceux-ci avaient un âge médian de 33 ans, et leur volume expiratoire maximal par seconde (VEMS) s'établissait à $64 \%$ de celui prévu. Lorsque le VEMS et la dépression des participants étaient maintenus constants, les chercheurs constataient une corrélation négative significative entre le total des heures d'activité par jour et l'état de fatigue général $(\beta=-0,735$, $p=0,03)$. Ils remarquaient également une tendance négative entre le total des heures d'activité par jour et la fatigue physique $(\beta=-0,579$, $p=0,09)$. Conclusion : la présente étude est la première à démontrer que, chez les adultes atteints de FK, un plus fort taux d'activité s'associe à une diminution de la fatigue générale et physique lors des contrôles de la fonction pulmonaire et de la dépression. Ainsi, l'activité physique peut réduire le taux de fatigue générale et physique chez les personnes atteintes de FK.

Cystic fibrosis (CF) is an autosomal, recessive genetic disease affecting multiple organs of the body. People with CF experience a variety of physical and psychologi- cal symptoms; fatigue is one of the most common, causing significant distress in approximately one-third of this patient population. ${ }^{1}$ Because the median age of survival

From the: *Department of Physical Therapy; $¥$ Rehabilitation Science Institute, Faculty of Medicine, University of Toronto; $†$ Toronto Adult Cystic Fibrosis Centre, Respirology Program; \&Mobility Program Clinical Research Unit, Keenan Research Centre, Li Ka Shing Knowledge Institute, St. Michael's Hospital, Toronto.

Correspondence to: Kenneth Wu, Toronto Adult Cystic Fibrosis Centre, Respirology Program, St. Michael's Hospital, 6101 Donnelly Wing, 30 Bond St., Toronto, 0N M5B 1W8; wuk@smh.ca.

Contributors: All authors designed the study; or collected, analyzed, or interpreted the data; and drafted or critically revised the article and approved the final draft.

Competing Interests: None declared.

This research was completed by five students in partial fulfillment of the requirements for a Master of Science in Physical Therapy at the University of Toronto.

Acknowledgements: The authors thank Lesley Gaskin, Katie Griffin, Jennifer Pike, and Leena Rizvi for their assistance with participant recruitment. 
for people with CF continues to increase, reaching 51.8 years in 2014 in Canada, ${ }^{2}$ fatigue is becoming an even more important issue.

In this study, we defined fatigue as a subjective lack of physical, mental, or emotional energy that an individual perceives as interfering with his or her usual and desired activities. This categorization is based on the Multidimensional Fatigue Inventory (MFI). ${ }^{3}$ Physical fatigue refers to one's perception of the degree of deterioration in one's physical condition and the perceived reduction in the amount of physical activity that one can perform now. Reduced activity refers to the reduced amount of physical activity compared with what one has performed in the past (the behavioural consequence of fatigue). Mental fatigue is one's degree of inability to concentrate during usual and desired activities. Emotional or moodrelated fatigue concerns one's reduced intention to perform usual and desired activities (reduced motivation). We also looked at general fatigue - that is, the level of fatigue not pertaining to any specific aspect of fatigue.

Research has shown that greater amounts of physical activity of varying intensity are associated with decreased levels of fatigue in chronic conditions such as chronic obstructive pulmonary disease, ${ }^{4}$ rheumatoid arthritis, ${ }^{5}$ systemic lupus erythematosus, ${ }^{6}$ and multiple sclerosis. ${ }^{7}$ To our knowledge, no prior study has examined the relationship between level of fatigue and amount of physical activity in the adult CF population. Understanding this relationship may help clinicians to develop strategies that use physical activity to mitigate the level of fatigue in adults with CF. The purpose of this study was to evaluate the relationship between amount of physical activity and level of fatigue in adults with CF.

\section{METHODS}

\section{Participants}

Individuals were eligible to participate in this study if they were aged 18 years or older and had been diagnosed with CF by sweat chloride testing, genotyping, or both. Those who had received oral or intravenous antibiotics because of pulmonary exacerbations for 1 month or longer before recruitment began or who had a history of lung transplant were excluded; the former group is considered atypical and may either be too sick to participate in any physical activities, unrelated to the level of fatigue, feel exceptionally fatigued because of the prolonged pulmonary exacerbation, or both.

\section{Measures}

\section{Habitual Activity Estimation Scale}

We chose the Habitual Activity Estimation Scale (HAES) ${ }^{8}$ to quantify physical activity. The HAES estimates the amount of time an individual spends performing activities of varying intensity. To complete the scale, participants identified the percentage of time in four time periods during a typical weekday in which they were very active, somewhat active, somewhat inactive, and inactive, as classified by the HAES outcome measure. The four time periods were the time between getting out of bed and starting breakfast; between finishing breakfast and starting lunch; between finishing lunch and starting supper; and between finishing supper and bedtime. The HAES classifies activities that result in sweating, dramatic increase in heart rate, and heavy breathing as "very active"; lighter activities involving movement and increased heart rate as "somewhat active"; any activity performed sitting down as "somewhat inactive" (i.e., during meals); and any activity performed lying down as "inactive" (i.e., during bedtime).

Participants then identified the time they got out of bed in the morning; the time at which they had breakfast, lunch, and supper; and the time they went to bed in the evening on a typical weekday. Participants also estimated the duration of their breakfast, lunch, and dinner on a typical weekday. We tabulated the duration of each of the four periods and computed the number of hours participants spent on activities of different intensity over a 24-hour period by multiplying the sum of the percentage of time on activities of different intensity during a 24-hour period by 24 hours. The HAES has been shown to have good reliability and validity in adults with CF. ${ }^{9}$

\section{Multidimensional Fatigue Inventory-20}

To measure the amount of fatigue in an individual, we elected to use the Multidimensional Fatigue Inventory20 (MFI-20) ${ }^{10}$ because we were interested in the multidimensional aspect of fatigue. The MFI-20 is a self-report questionnaire that consists of 20 items scored on a scale ranging from 1 to 5 . These 20 items are organized into five subscales that measure general fatigue and four types of domain-specific fatigue: physical fatigue, reduced activity, reduced motivation, and mental fatigue. The questionnaire specifically asks participants to rate how they have felt lately regarding their level of fatigue. Each subscale total ranges from 4 to 20 points; higher scores indicate greater fatigue. The MFI-20 has been shown to have good internal consistency as well as construct and convergent validity in different patient populations and professional groups. ${ }^{3,10}$ To date, psychometric properties of this questionnaire are not available for the CF patient population.

\section{Hospital Anxiety and Depression Scale-Depression Subscale}

Because levels of both fatigue and physical activity can be hampered by depression ${ }^{11-13}$ and people with $\mathrm{CF}$ have been reported to have higher incidences of depression, ${ }^{14}$ we used the Depression subscale of the Hospital Anxiety and Depression Scale (HADS) to identify the presence and severity of depression. ${ }^{15}$ The HADS Depression subscale (HADS-D) is a self-report questionnaire 
consisting of seven items, each measuring depression on a 4-point Likert scale (ranging from 0 to 3). A total score of 0-7 is categorized as a "non-case," 8-10 as a "doubtful case," and 11-21 as a "definite case" of depression. Somatic symptoms of depression, such as insomnia and weight loss, are not included in the questionnaire, thus making the measure suitable for use with the chronically ill population. Good internal consistency and construct validity have been reported for the HADS in general hospital patients, ${ }^{16}$ and it has been used in previous studies with adults with CF. ${ }^{17,18}$

\section{Demographic data}

Demographic and clinical data were extracted from the participants' medical charts and the Toronto Cystic Fibrosis Registry, housed at the Hospital for Sick Children in Toronto. This registry prospectively collects data from every clinic visit of patients followed at St. Michael's Hospital who have provided informed consent. The data extracted included each participant's age, sex, genotype, most recent forced expiratory volume in 1 second $\left(\mathrm{FEV}_{1}\right)$, and forced vital capacity (FVC) - both the actual value (in litres) and the percentage predicted, as calculated by the Hankinson reference equation ${ }^{19}$ - BMI, and whether the participant had any record of growing Pseudomonas aeruginosa or Burkholderia cepacia complex (BCC). Pseudomonas aeruginosa is one of the most common bacteria grown in adults with $\mathrm{CF}^{2}$ and BCC can cause life-threatening pulmonary infections in patients with CF. ${ }^{20}$ Studies of patients with CF who are infected with BCC have found that they have worse clinical outcomes than those with no BCC infection. ${ }^{21-24}$ These microbiological data were collected to help determine the representativeness of our sample.

\section{Study design}

For this cross-sectional study, patients were recruited while they were attending the outpatient CF clinic in the Toronto Adult Cystic Fibrosis Centre at St. Michael's Hospital over a 6-month period. Self- and investigatoradministered paper questionnaires were completed at participants' chosen location-either in their home or in a place close to their home. After patients had provided informed consent for this study, the investigators guided them to complete the HAES. Participants then independently filled out the MFI-20 and then the HADSD. Approval for this study was obtained from the St. Michael's Hospital and University of Toronto research ethics boards (REB nos. 12-317 and 28591, respectively).

\section{Statistics}

Descriptive statistics were computed on the demographic and clinical data, the scores on the different fatigue subdomains, the total number of hours that participants spent in different levels of physical activity, and depression score. Continuous variables were summarized by reporting the median and range. Categorical variables were summarized as frequency and proportion.
Simple linear regression models were used to quantify the relationship between the total number of hours spent being somewhat active and very active ${ }^{25}$ and each of the five fatigue scores. To ensure that the effects of possible confounders were taken into consideration, the best multivariate linear regression model was chosen by using a purposeful selection technique. ${ }^{26}$ The normality assumption was assessed for all variables by examining the histograms.

All analyses were performed using $\mathrm{R}$, version 3.1.1 ( Foundation for Statistical Computing, Vienna, Austria). ${ }^{27}$ All $p$ values were two-sided and deemed significant if they were less than 0.05 . No corrections for multiplicity were made.

\section{RESULTS}

A total of 51 adults with CF were approached for the study, and 22 agreed to participate (10 men, 45.5\%; 12 women, 54.5\%). The median age of participants was 33 (range 18-67) years, and their median BMI was 22.2 (range 17.6-28.3) $\mathrm{kg} / \mathrm{m}^{2}$. Their median $\mathrm{FEV}_{1}$ and FVC were $64 \%$ (range $27 \%-100 \%$ ) and $86 \%$ (range $42 \%$ $106 \%)$ predicted, respectively. Two participants (9\%) grew BCC, and 12 (55\%) grew Pseudomonas aeruginosa. In our clinic, the prevalence of BCC and Pseudomonas aeruginosa in 2014 was $8.6 \%$ and $50.7 \%$, respectively. Of the 22 participants, $32 \%$ had homozygous delta F508, and $46 \%$ had heterozygous delta F508. The median score for depression was 2.5 (range 0-8). Clinical and demographic data are shown in Table 1.

The scores for fatigue and physical activity are shown in Table 2. Participants rated their general fatigue (median) as 11.5 , which is higher than all domain-specific fatigue. The median scores for the remaining four domains were, from highest to lowest, 10.0 for physical fatigue, 9.0 for reduced activity, 8.5 for mental fatigue, and 7.0 for reduced motivation.

On a weekday, participants spent a median of 8.0 (range 5.8-9.5) hours being inactive and 9.9 (range 4.1-14.0) hours being somewhat inactive. They spent a median of 0.4 (range 0-1.6) hours (i.e., 24 [range 0-96] min]) being very active and 5.8 (range 1.5-9.4) hours being somewhat active. Their total median active hours on a weekday (being both somewhat active and very active) was 6.1 (range 2.8-10.5).

Table 3 shows the univariate and multivariable regression analyses between different fatigue domains and total active hours over the weekday. The univariate regression analysis demonstrated no significant relationship between total active hours and the scores from the five different fatigue domains.

Using purposeful selection, ${ }^{26} \mathrm{FEV}_{1}$ and depression were the most commonly chosen confounders. All models were thus adjusted for $\mathrm{FEV}_{1}$ and depression to allow for consistency among them. When holding both $\mathrm{FEV}_{1}$ and depression constant, there was a significant negative correlation between general fatigue and total active hours $(\beta=-0.735$, 
Table 1 Clinical and Demographic Characteristics of Participants

\begin{tabular}{lc}
\hline Characteristic & No. (\%) of participants* \\
\hline Sex & \\
Male & $10(45.5)$ \\
Female & $12(54.5)$ \\
Age; median (range) & $33(18-67)$ \\
$\quad<40$ y & $15(68.2)$ \\
$\geq 40$ y & $7(31.8)$ \\
BMl, kg/m²; median (range) & $22.2(17.6-28.3)$ \\
FEV 1 (\% predicted) & $64(27-100)$ \\
FVC (\% predicted) & $86(42-106)$ \\
Burkholderia cepacia complex & $2(9)$ \\
Pseudomonas aeruginosa & $12(55)$ \\
Genotype & \\
Homozygous delta F508; \% & 32 \\
Heterozygous delta F508; \% & 46 \\
Depression score on HADS-D & $2.5(0-8)$ \\
\hline
\end{tabular}

*Unless otherwise indicated.

$\mathrm{FEV}_{1}=$ forced expiratory volume in 1 second; FVC = forced vital capacity;

HADS-D = Hospital Anxiety and Depression Scale - Depression Subscale.

$p=0.03$ ). Also, after adjusting for both $\mathrm{FEV}_{1}$ and depression, we found a negative trend between the number of total active hours and score on physical fatigue, although it was only borderline significant $(\beta=-0.579, p=0.09)$. For reduced activity, mental fatigue, and reduced motivation, adjusting for lung function and depression did not change the overall interpretation of the results.

\section{DISCUSSION}

The results show that this cohort of adults with CF had a higher level of general fatigue than did the general population, and they had a larger range in each type of domain-specific fatigue than did the general population. ${ }^{28}$ These results are generally consistent with those of a previous study with the CF patient population. ${ }^{13}$

While being awake for 16 hours on a weekday, our cohort spent about 6 hours being physically active, ranging from slightly less than 3 hours to 10.5 hours being both somewhat active and very active. This result is similar to what was reported in a previous study that used the HAES in school-aged patients (8-20 y) with CF. ${ }^{10}$ When our participants spent less than 3 hours on a typical weekday being physically active, it meant that they spent
Table 2 Results from the MFI-20 and HAES

\begin{tabular}{lc}
\hline Measure & $\begin{array}{c}\text { Score or hours, } \\
\text { median (range) }\end{array}$ \\
\hline MFI-20: fatigue domain & \\
General fatigue & $11.5(6-18)$ \\
Physical fatigue & $10.0(4-18)$ \\
Reduced activity & $9.0(4-14)$ \\
Mental fatigue & $8.5(4-14)$ \\
Reduced motivation & $7.0(4-14)$ \\
HAES: weekday level of activity & \\
Inactive (e.g., sleeping) & $8.0(5.8-9.5)$ \\
Somewhat inactive & $9.9(4.1-14.0)$ \\
Total active* & $6.1(2.8-10.5)$ \\
$\quad$ Somewhat active & $5.8(1.5-9.4)$ \\
$\quad$ Very active & $0.4(0.0-1.6)$ \\
\hline
\end{tabular}

*The number of hours participants were both somewhat active and very active. MFI-20 = Multidimensional Fatigue Index-20; HAES = Habitual Activity Estimation Scale.

more than 21 hours being somewhat inactive or inactive-that is, they were either in a sitting position or lying down or sleeping, respectively. Physical inactivity has been found to be associated with poor bone health, ${ }^{29,30}$ and it contributes to exercise intolerance and skeletal muscle weakness in adults with CF. ${ }^{31}$ Considering that our cohort was living in the community, some people with CF were living a very sedentary lifestyle.

On a weekday, our cohort spent a median of 24 minutes (or $0.4 \mathrm{~h}$ ) being very active, ranging from 0 minutes to 96 minutes $(1.6 \mathrm{~h})$. The majority of total hours being physically active were spent being somewhat active-a median of almost 6 hours, ranging from 1.5 to 9.4 hours. Again, some participants were quite physically active and exercised for more than 1.5 hours, and some did not exercise at all or spent only 1.5 hours being somewhat active, indicating that in this study, participants with $\mathrm{CF}$ had a wide range of physical activity levels.

When controlling for lung function and level of depression, we detected a significant negative correlation between the total number of hours spent being physically active and general fatigue. Also, when holding lung function and level of depression constant, a negative trend was found between the number of hours being physically active and physical fatigue, although it did not

Table 3 Linear and Multiple Regression Analyses of Total Active Hours on a Weekday and Scores from the Domains of Fatigue

\begin{tabular}{|c|c|c|c|c|}
\hline \multirow[b]{2}{*}{ Domain of fatigue } & \multicolumn{2}{|c|}{ Univariate } & \multicolumn{2}{|c|}{ Multivariable* } \\
\hline & Estimated $\beta$ coefficient (SE) & $p$-value & Estimated $\beta$ coefficient (SE) & $p$-value \\
\hline General fatigue & $-0.486(0.332)$ & 0.16 & $-0.735(0.302)$ & 0.03 \\
\hline Physical fatigue & $-0.260(0.384)$ & 0.51 & $-0.579(0.320)$ & 0.09 \\
\hline Reduced activity & $0.106(0.290)$ & 0.72 & $0.077(0.318)$ & 0.81 \\
\hline Mental fatigue & $0.026(0.335)$ & 0.94 & $-0.015(0.367)$ & 0.97 \\
\hline Reduced motivation & $0.209(0.304)$ & 0.50 & $-0.027(0.269)$ & 0.92 \\
\hline
\end{tabular}

* Models adjusted for Hospital Anxiety and Depression Scale-Depression Subscale and forced expiratory volume in 1 second. 
reach statistical significance. Those associations were not significant if lung function and level of depression were not controlled for statistically. These results indicate that both lung function and level of depression are main confounders for the relationship between amount of physical activity and level of fatigue. No evidence of an association was found between the number of hours spent on physical activity and reduced activity, mental fatigue, or reduced motivation, whether lung function and level of depression were controlled for or not.

The time spent being inactive may potentially be a confounder. This is because some studies have reported a negative association between amount of sleep and level of fatigue, ${ }^{32}$ and some have shown that the number of hours spent sleeping is associated with the amount of exercise performed by adults with CF. ${ }^{33}$ We carried out a sensitivity analysis by also adjusting for the number of hours being inactive; these results indicated that number of hours of sleep was not a confounder in our study.

On the basis of our analysis, it appears that level of physical activity is associated only with the perception of fatigue (i.e., physical fatigue), not the behavioural consequences of it (i.e., reduced activity). This result is likely because our participants were relatively young, with relatively good lung function, and they need to maintain their activities of daily living, whether they feel tired or not. Hence, the behavioural aspect of fatigue has little association with level of physical activity. Besides, the range of scores in our cohort for the reduced activity subscale of fatigue was relatively small, which may have limited our ability to detect any relationship between physical activity and this domain of fatigue.

We were also unable to find any association between level of physical activity and the emotional and psychological aspects of fatigue. In our cohort, the highest depression score on the HADS-D was still relatively low; only one participant fell into the "doubtful cases" category of depression. ${ }^{15}$ This small range of emotional and psychological aspects of fatigue may, again, limit our ability to detect any relationship between physical activity and the mental fatigue and reduced motivation domains.

The association we found between general and physical fatigue and level of physical activity generates three possible interpretations. First, more physical activity may lead to less general and physical fatigue, and vice versa. If this hypothesis is valid, this study provides support for yet another benefit of physical activity, that is, it is a means of mitigating the level of general and physical fatigue in people with CF. As one engages in more physical activity, muscles become stronger, and daily activities are thus less exhausting.

A second interpretation is that it is logical to assume that the more general and physical fatigue one experiences, the less likely one is to engage in any physical activity and vice versa. Third, the relationship between general and physical fatigue and physical activity may be a cyclical negative relationship, implying that both our first and second interpretations are true. However, a study such as this one, which looks at only the association, will not be able to tease out the relationship between physical activity and fatigue. The only way to truly unravel this relationship would be to conduct a randomized controlled trial to determine whether level of physical activity affects level of fatigue in people with CF.

This study had several limitations. First, the sample size was relatively small. Because the HAES had never been administered by telephone, the participants needed to fill out the questionnaire with the guidance of the investigator in person. Because personnel were unavailable when the participants came into the clinic, the participants had to schedule a separate research visit to fill out their questionnaire. This limited the pool of participants to those who lived close to the hospital. The small sample size limited our ability to detect certain relationships and the robustness of the results.

Second, because the main goal of this study was to generate hypotheses for any correlations found between physical activity and the different fatigue domains, the $p$ values were not corrected for multiplicity. This increased the probability of detecting a spurious result. Future studies are required to validate the associations found in this study.

A third limitation was that this study used the HAES as the only outcome measure for physical activity and did not consider other physical activity measurements. The HAES was chosen because its validity has been demonstrated in the CF patient population. The HAES is, however, a relatively rigid tool in that it only considers habitual activities that are performed at least three times per week on Tuesday, Wednesday, Thursday, and Saturday. It excludes habitual activities that are done on Monday, Friday, and Sunday. During the data collection period, anecdotal reports from several participants indicated that they were quite active on days that the HAES did not consider; they may have performed highintensity physical activities twice per week, but these activities could not be included because they did not meet the criteria for being habitual.

Future studies need to recruit a larger sample-for example, by using a multi-centre trial. This would better represent the patient population and better detect the associations between level of physical activity and fatigue. Also, we recommend that studies use multiple outcome measures for each variable and thereby overcome the weaknesses of each one. For example, using an accelerometer to measure habitual physical activity might provide more objective data. Future studies should also consider using a prospective cohort study design to examine the change in level of fatigue using physical activity, exercise, or both as an intervention. 


\section{CONCLUSION}

High levels of fatigue were seen in adults with CF with moderate impairments of lung function. They maintained considerably different levels of physical activity, ranging from a very sedentary lifestyle to exercising for 1.6 hours on a weekday. This study is to our knowledge the first to demonstrate that, in adults with $\mathrm{CF}$, a higher level of physical activity is associated with a lower level of general and physical fatigue when controlling for lung function and level of depression. Physical activity may be used as a means of mitigating the level of general and physical fatigue in people with CF. Future studies are needed to examine the change in level of fatigue when using physical activity, exercise, or both as an intervention.

\section{KEY MESSAGES}

\section{What is already known on this topic}

Fatigue is one of the most common symptoms reported by people with cystic fibrosis (CF), and it causes significant distress in approximately one-third of this patient population. ${ }^{1}$ Greater amounts of physical activity of varying intensity have been shown to be associated with decreased levels of fatigue in people with various chronic conditions. ${ }^{4-7}$

\section{What this study adds}

This study is the first to demonstrate that, in adults with CF, a higher level of physical activity is associated with a lower level of general and physical fatigue when controlling for lung function and level of depression.

\section{REFERENCES}

1. Sawicki GS, Sellers DE, Robinson WM. Self-reported physical and psychological symptom burden in adults with cystic fibrosis. J Pain Symptom Manage. 2008;35(4):372-80. http://dx.doi.org/10.1016/ j.jpainsymman.2007.06.005. Medline:18215497

2. Canadian Cystic Fibrosis Registry. 2014 annual report [Internet]. Toronto: Cystic Fibrosis Canada; 2014 [cited 2017 Apr 20]. Available from: https://cysticfibrosis.uberflip.com/i/705240-cystic-fibrosiscanada-registry.

3. Smets EM, Garssen B, Bonke B, et al. The Multidimensional Fatigue Inventory (MFI) psychometric qualities of an instrument to assess fatigue. J Psychosom Res. 1995;39(3):315-25. http://dx.doi.org/ 10.1016/0022-3999(94)00125-O. Medline:7636775

4. Lewko A, Bidgood PL, Jewell A, et al. Evaluation of multidimensional COPD-related subjective fatigue following a pulmonary rehabilitation programme. Respir Med. 2014;108(1):95-102. http:// dx.doi.org/10.1016/j.rmed.2013.09.003. Medline:24084060

5. Neuberger GB, Press AN, Lindsley HB, et al. Effects of exercise on fatigue, aerobic fitness, and disease activity measures in persons with rheumatoid arthritis. Res Nurs Health. 1997;20(3):195-204. http://dx.doi.org/10.1002/(SICI) 1098-240X(199706)20:3<195::AIDNUR3>3.0.CO;2-D. Medline:9179174

6. Daltroy LH, Robb-Nicholson C, Iversen MD, et al. Effectiveness of minimally supervised home aerobic training in patients with systemic rheumatic disease. Br J Rheumatol. 1995;34(11):1064-9. http://dx.doi.org/10.1093/rheumatology/34.11.1064. Medline:8542209

7. Asano M, Finlayson ML. Meta-analysis of three different types of fatigue management interventions for people with multiple sclerosis: exercise, education, and medication. Mult Scler Int. 2014;2014:798285. http://dx.doi.org/10.1155/2014/798285.

8. Hay JA, Cairney J. Development of the Habitual Activity Estimation Scale for clinical research: a systematic approach. Pediatr Exerc Sci. 2006;18(2):193-202. http://dx.doi.org/10.1123/pes.18.2.193.

9. Wells GD, Wilkes DL, Schneiderman-Walker J, et al. Reliability and validity of the Habitual Activity Estimation Scale (HAES) in patients with cystic fibrosis. Pediatr Pulmonol. 2008;43(4):345-53. http:// dx.doi.org/10.1002/ppul.20737. Medline:18306334

10. Lin JM, Brimmer DJ, Maloney EM, et al. Further validation of the Multidimensional Fatigue Inventory in a US adult population sample. Popul Health Metr. 2009;7(1):18-29. http://dx.doi.org/ 10.1186/1478-7954-7-18. Medline:20003524

11. Al-shair K, Kolsum U, Dockry R, et al. Biomarkers of systemic inflammation and depression and fatigue in moderate clinically stable COPD. Respir Res. 2011;12(1):3-8. http://dx.doi.org/10.1186/ 1465-9921-12-3. Medline:21208443

12. Schüz N, Walters JA, Cameron-Tucker H, et al. Patient anxiety and depression moderate the effects of increased self-management knowledge on physical activity: a secondary analysis of a randomised controlled trial on health-mentoring in COPD. COPD. 2015;12(5):502-9. http://dx.doi.org/10.3109/15412555.2014.995289. Medline:25774660

13. Jarad NA, Sequeiros IM, Patel P, et al. Fatigue in cystic fibrosis: a novel prospective study investigating subjective and objective factors associated with fatigue. Chron Respir Dis. 2012;9(4):241-9. http://dx.doi.org/10.1177/1479972312464236. Medline:23129802

14. Quittner AL, Barker DH, Snell C, et al. Prevalence and impact of depression in cystic fibrosis. Curr Opin Pulm Med. 2008;14(6):5828.http://dx.doi.org/10.1097/MCP.0b013e3283121cf1. Medline:18812836

15. Zigmond AS, Snaith RP. The Hospital Anxiety and Depression Scale. Acta Psychiatr Scand. 1983;67(6):361-70. http://dx.doi.org/10.1111/ j.1600-0447.1983.tb09716.x. Medline:6880820

16. Michopoulos I, Douzenis A, Kalkavoura C, et al. Hospital Anxiety and Depression Scale (HADS): validation in a Greek general hospital sample. Ann Gen Psychiatry. 2008;7(1):4-8. http://dx.doi.org/ 10.1186/1744-859X-7-4. Medline:18325093

17. Havermans T, Colpaert K, Dupont LJ. Quality of life in patients with cystic fibrosis: association with anxiety and depression. J Cyst Fibros. 2008;7(6):581-4. http://dx.doi.org/10.1016/j.jcf.2008.05.010. Medline:18692444

18. Yohannes AM, Willgoss TG, Fatoye FA, et al. Relationship between anxiety, depression, and quality of life in adult patients with cystic fibrosis. Respir Care. 2012;57(4):550-6. http://dx.doi.org/10.4187/ respcare.01328. Medline:22004950

19. Hankinson JL, Odencrantz JR, Fedan KB. Spirometric reference values from a sample of the general U.S. population. Am J Respir Crit Care Med. 1999;159(1):179-87. http://dx.doi.org/10.1164/ ajrccm.159.1.9712108. Medline:9872837

20. Goldmann DA, Klinger JD. Pseudomonas cepacia: biology, mechanisms of virulence, epidemiology. J Pediatr. 1986;108(5 Pt 2):806-12. http://dx.doi.org/10.1016/S0022-3476(86)80749-1. Medline:3517271

21. Hauser AR, Jain M, Bar-Meir M, et al. Clinical significance of microbial infection and adaptation in cystic fibrosis. Clin Microbiol Rev. 2011;24(1):29-70. http://dx.doi.org/10.1128/CMR.00036-10. Medline:21233507

22. France MW, Dodd ME, Govan JR, et al. The changing epidemiology of Burkholderia species infection at an adult cystic fibrosis centre. J Cyst Fibros. 2008;7(5):368-72. http://dx.doi.org/10.1016/ j.jcf.2008.01.002. Medline:18276200

23. Jones AM, Dodd ME, Govan JR, et al. Burkholderia cenocepacia and Burkholderia multivorans: influence on survival in cystic fibrosis. Thorax. 2004;59(11):948-51. http://dx.doi.org/10.1136/ thx.2003.017210. Medline:15516469 
24. Stephenson AL, Tom M, Berthiaume Y, et al. A contemporary survival analysis of individuals with cystic fibrosis: a cohort study. Eur Respir J. 2015;45(3):670-9. http://dx.doi.org/10.1183/ 09031936.00119714. Medline:25395034

25. Dimeo FC, Stieglitz RD, Novelli-Fischer U, et al. Effects of physical activity on the fatigue and psychologic status of cancer patients during chemotherapy. Cancer. 1999;85(10):2273-7 http://dx.doi.org/ 10.1002/(SICI) 1097-0142(19990515)85:10<2273::AID-CNCR24>3.0.CO;2-B. Medline:10326708

26. Bursac Z, Gauss CH, Williams DK, et al. Purposeful selection of variables in logistic regression. Source Code Biol Med. 2008;3(1):1724. http://dx.doi.org/10.1186/1751-0473-3-17. Medline:19087314

27. R: A language and environment for statistical computing [Internet]. Vienna: R Foundation for Statistical Computing; 2014 [cited 2016 Oct 8]. Available from: http://www.R-project.org/.

28. Schwarz R, Krauss O, Hinz A. Fatigue in the general population. Onkologie. 2003;26(2):140-4. Medline:12771522
29. Haworth CS, Selby PL, Webb AK, et al. Low bone mineral density in adults with cystic fibrosis. Thorax. 1999;54(11):961-7. http:// dx.doi.org/10.1136/thx.54.11.961. Medline:10525552

30. Sermet-Gaudelus I, Castanet M, Retsch-Bogart G, et al. Update on cystic fibrosis-related bone disease: a special focus on children. Paediatr Respir Rev. 2009;10(3):134-42. http://dx.doi.org/10.1016/ j.prrv.2009.05.001. Medline:19651384

31. Troosters T, Langer D, Vrijsen B, et al. Skeletal muscle weakness, exercise tolerance and physical activity in adults with cystic fibrosis. Eur Respir J. 2009;33(1):99-106. http://dx.doi.org/10.1183/ 09031936.00091607. Medline:18715878

32. Darwent D, Dawson D, Paterson JL, et al. Managing fatigue: it really is about sleep. Accid Anal Prev. 2015;82:20-6. http://dx.doi.org/ 10.1016/j.aap.2015.05.009. Medline:26026969

33. Currie S, Greenwood K, Weber L, et al. Physical activity levels in individuals with cystic fibrosis-related diabetes. Physiotherapy Canada. 2017;69(2):171-7. http://dx.doi.org/10.3138/ptc.2015-92EP. 